\title{
New Procedure of Finding an Initial Basic Feasible Solution of the Time Minimizing Transportation Problems
}

\author{
Mollah Mesbahuddin Ahmed1', Md. Amirul Islam1, Momotaz Katun², Sabiha Yesmin'1, \\ Md. Sharif Uddin'1 \\ ${ }^{1}$ Department of Mathematics, Jahangirnagar University, Savar, Dhaka, Bangladesh \\ ${ }^{2}$ Department of Mathematics, Bangladesh University, Dhaka, Bangladesh \\ Email: mesbah 1972@yahoo.com, amirulmaths01@yahoo.com, zabir2324@gmail.com, \\ shabihay23@gmail.com, msharifju@yahoo.com
}

Received 28 September 2015; accepted 26 October 2015; published 29 October 2015

Copyright (C) 2015 by authors and Scientific Research Publishing Inc.

This work is licensed under the Creative Commons Attribution International License (CC BY). http://creativecommons.org/licenses/by/4.0/

cC) (i) Open Access

\begin{abstract}
Minimization of transportation time is a great concern of the transportation problems like the cost minimizing transportation problems. In this writing, a transportation algorithm is developed and applied to obtain an Initial Basic Feasible Solution (IBFS) of transportation problems in minimizing transportation time. The developed method has also been illustrated numerically to test the efficiency of the method where it is observed that the proposed method yields a better result.
\end{abstract}

Keywords

Transportation Problem, Initial Basic Feasible Solution, Minimizing, Transportation Time

\section{Introduction}

A special class of Linear Programming Problem is transportation problem, where the main objective is to minimize the cost of distributing a product from a number of sources to a number of destinations. This type of problem is known as cost minimizing transportation problem. The problem of minimizing transportation cost has been studied since long and is well known by [1]-[15].

Again, in the process of transporting of urgent material, such as weapons used in military operations, rescue equipments, equipments used for dealing with emergency, medical treatment things and the fresh foods with 
short storage period, where the speed of delivery is more important than the transportation cost. This type of transportation problem is known as time minimizing transportation problem where the objective is to minimize the transporting time rather than the cost of transportation.

An initial basic feasible solution for minimizing the time of transportation can be obtained by using any well known methods such as, North West Corner Method (NWCM), Least Cost Method (LCM), Vogel's Approximation Method (VAM) and Extremum Difference Method (EDM). The time minimizing transportation problem had also been studied by a good number of researchers [16]-[20] and they introduced various algorithms for solving time minimizing transportation problems. Garfinkel and Rao in 1971 solved time minimizing transportation problems [21]. Hammer [16] and Szwarc [22] used labeling techniques to solve such kind of problems respectively in 1969 and 1971. In [23], Nikolic proposed an algorithm to obtain the minimum of the total transportation time. Very recently M. Sharif Uddin [18] has developed an efficient technique of minimizing the time of a transportation problem.

\section{Proposed Procedure of Finding an Initial Basic Feasible Solution}

It is considered that the readers are well acquainted with transportation problem. Basing on this consideration, a new procedure of finding an initial basic feasible solution of the time minimizing transportation problems is been illustrated below:

- Step-1: Identify the Largest Element (LE) of every row and every column in the transportation table and write down them in outer column of the supply and lower row of the demand.

- Step-2: Determine the magnitude of the difference of row largest element and column largest element corresponding to each element.

- Step-3: Place the value obtained in step-2 on the right bottom of the corresponding elements.

- Step-4: Place the Row Distribution Indicators (RDI) and the Column Distribution Indicators (CDI) just after and below the supply limits and demand requirements respectively within first bracket, which are the difference of the largest and nearest-to-largest (Second largest) of right bottom entries. If there are two or more largest entries, the RDI or CDI is to be considered as zero.

- Step-5: Identify the largest number among the RDI and CDI in each level. Choose the smallest time unit along the highest RDI or CDI. If there are two or more number of highest RDI or CDI; choose that highest indicator along which the smallest time element is present. If there are two or more number of smallest time element, choose any one of those arbitrarily.

- Step-6: Allocate minimum of supply/demand values on the left top of the corresponding smallest time unit selected in Step-5.

- Step-7: Check whether exactly one of the row/column corresponding to the selected cell has zero supply/ zero demand, respectively. If so, delete the row/column which has the zero supply/zero demand. Again if it is found that both the supply and demand has become zero corresponding to the selected cell, delete either the row or column but not both.

- Step-8: Match the supply/demand of the left out row/column with the remaining demands/supplies of the undeleted columns/row.

- Step-9: Repeat Step: 4 to 6 until all the rim requirements are satisfied.

- Step-10: Determine the largest time $T_{k}$ corresponding to basic cells.

\section{Algorithm for Optimality Test}

Algorithm for finding the optimal time for time minimization transportation problems are described below:

- Step-1: Determine an initial basic feasible solution using above method.

- Step-2: Determine the largest time $T_{k}$ corresponding to the basic cells and cross off all non-basic cells $t_{i j} \geq T_{j}$.

- Step-3: Construct a loop for the basic cells corresponding to largest time $T_{k}$ including a non-basic cell in such a way that the allotment in the cell with $T_{k}$ can be shifted to the non-basic cell in the loop by readjustment of row and column sum, the value at $T_{k}$ cell is zero and no variables becomes zero or negative. If no such loop can be formed, the solution under test is optimum. Otherwise move to the next step.

- Step-4: Repeat the procedure until an optimum basic feasible solution is obtained. 


\section{Illustrative Example}

\subsection{Example-1}

Table 1 shows the time required to shift a load from origins to destinations. It is required to find the optimum plan for shipment to minimize the time of shipment.

Table 1. Data of the example-1.

\begin{tabular}{cccccc}
\hline Origins & \multicolumn{3}{c}{ Destinations } & D $_{3}$ & Suply \\
\cline { 2 - 5 } & $\mathbf{D}_{\mathbf{1}}$ & 13 & $\mathbf{D}_{\mathbf{2}}$ & 14 & $\mathbf{1 3}$ \\
$\mathbf{O}_{\mathbf{1}}$ & 8 & 12 & 21 & $\mathbf{2 0}$ \\
$\mathbf{O}_{3}$ & 15 & 17 & $\mathbf{5}$ & $\mathbf{1 1}$ \\
\hline
\end{tabular}

\subsubsection{Initial Basic Feasible Solution}

From the above table it is seen that total supply and total demand are equal. Hence the given transportation problem is a balanced one. Obtaining IBFS for Example-1 using the Proposed Algorithm is shown in Table 2.

Table 2. Initial basic feasible solution of example-1using proposed algorithm.

\begin{tabular}{|c|c|c|c|c|c|c|c|c|}
\hline \multirow{2}{*}{ Origins } & \multicolumn{3}{|c|}{ Destinations } & \multirow{2}{*}{ Supply } & \multirow{2}{*}{ LE } & & \multirow{2}{*}{ RDI } & \\
\hline & $\mathbf{D}_{1}$ & $\mathbf{D}_{2}$ & $\mathbf{D}_{3}$ & & & & & \\
\hline $\mathbf{O}_{1}$ & $13_{6}$ & ${ }^{2} 21_{0}$ & ${ }^{11} 14_{0}$ & 13 & 21 & (6) & (0) & (0) \\
\hline $\mathbf{O}_{2}$ & ${ }^{12} 8_{6}$ & ${ }^{8} 12_{0}$ & $21_{0}$ & 20 & 21 & (6) & (0) & -- \\
\hline $\mathbf{O}_{3}$ & $15_{4}$ & ${ }^{5} 17_{2}$ & $19_{2}$ & 5 & 19 & (2) & (0) & (0) \\
\hline Demand & 12 & 15 & 11 & & & & & \\
\hline \multirow[t]{2}{*}{ LE } & 15 & 21 & 21 & & & & & \\
\hline & $(0)$ & (2) & (2) & & & & & \\
\hline \multirow[t]{2}{*}{ CDI } & -- & (2) & (2) & & & & & \\
\hline & -- & (2) & (2) & & & & & \\
\hline
\end{tabular}

We see that the number of basic variables is $5=(3+3-1)$ and the set of basic cells do not contain a loop. Thus the solution obtained is a basic feasible solution and the initial basic feasible solution is $x_{12}=2, x_{13}=11$, $x_{21}=12, x_{22}=8, x_{32}=5$ and the shipping time of basic cells are $t_{12}=21, t_{13}=14, t_{21}=8, t_{22}=12, t_{32}=17$.

Therefore, in order to complete the shifting it takes the time $T_{1}=\max \left\{t_{12}, t_{13}, t_{21}, t_{22}, t_{32}\right\}=\max \{21,14,8,12$, $17\}=21$ units of time.

\subsubsection{Optimality Test}

- Iteration-1: From the IBFS, it is found that the largest time is $T_{1}=21$, therefore we cross off the non-basic cell $(2,3)$ which contains equal time unit to $T_{1}$. Let us construct a loop for the basic cells corresponding to the largest time $T_{1}=21$ including the non-basic cell $(1,1)$ which is called entering cell. The constructed loop in this iteration is shown in Table 3.

Table 3. Consturucted loop in iteration-1.

\begin{tabular}{|c|c|c|c|c|}
\hline \multirow{2}{*}{ Origins } & \multicolumn{3}{|c|}{ Destinations } & \multirow{2}{*}{ Supply } \\
\hline & $\mathbf{D}_{1}$ & $\mathbf{D}_{2}$ & $\mathbf{D}_{3}$ & \\
\hline $\mathbf{O}_{1}$ & $\frac{13}{+}$ & $\frac{221}{-}$ & ${ }^{11} 14$ & 13 \\
\hline $\mathbf{O}_{2}$ & $\begin{array}{r}{ }^{12} 8 \\
-\quad- \\
\end{array}$ & $\begin{array}{c}812 \\
+ \\
\end{array}$ & & 20 \\
\hline $\mathbf{O}_{3}$ & 15 & ${ }^{5} 17$ & 19 & 5 \\
\hline Demand & 12 & 15 & 11 & \\
\hline
\end{tabular}


The allocation is readjusted in the corner of the loop and a new solution is obtained which is shown in Table 4.

Table 4. Readjusted allocation in iteration-1.

\begin{tabular}{ccccc}
\hline & \multicolumn{3}{c}{ Destinations } & Supply \\
\cline { 2 - 5 } Origins & $\mathbf{D}_{\mathbf{1}}$ & $\mathbf{D}_{2}$ & $\mathbf{D}_{3}$ & $\mathbf{1 3}$ \\
$\mathbf{O}_{\mathbf{1}}$ & ${ }^{2} 13$ & 21 & 11 & $\mathbf{2 0}$ \\
$\mathbf{O}_{2}$ & ${ }^{10} 8$ & ${ }^{10} 12$ & 21 & $\mathbf{5}$ \\
$\mathbf{O}_{3}$ & 15 & ${ }^{5} 17$ & 19 & $\mathbf{1 1}$ \\
\hline
\end{tabular}

- Iteration-2: Now largest time is $T_{2}=17$, therefore we cross off the cells $(1,2)$ and $(3,3)$ which contain larger time units than $T_{2}$. Let us construct a loop for the basic cells corresponding to the largest time $T_{2}=17$ including the non-basic cell $(3,1)$. The constructed loop in this iteration is shown in Table 5.

Table 5. Consturucted loop in iteration-2.

\begin{tabular}{|c|c|c|c|c|}
\hline \multirow{2}{*}{ Origins } & \multicolumn{3}{|c|}{ Destinations } & \multirow{2}{*}{ Supply } \\
\hline & $\mathbf{D}_{1}$ & $\mathbf{D}_{2}$ & $\mathbf{D}_{3}$ & \\
\hline $\mathbf{O}_{1}$ & ${ }^{2} 13$ & 2 & ${ }^{11} 14$ & 13 \\
\hline $\mathbf{O}_{2}$ & $\begin{array}{r}{ }^{10} 8 \\
-\end{array}$ & $\frac{{ }^{10} 12}{+}$ & & 20 \\
\hline $\mathbf{O}_{3}$ & $\begin{array}{r}15 \\
+ \\
\end{array}$ & $\begin{array}{l}{ }^{5} 17 \\
- \\
\end{array}$ & & 5 \\
\hline Demand & 12 & 15 & 11 & \\
\hline
\end{tabular}

Readjust the allocation in the corner of the loop, we obtain a new solution which is shown in Table 6.

Table 6. Readjusted allocation in iteration-2.

\begin{tabular}{ccccc}
\hline & \multicolumn{1}{c}{ Destinations } & \multicolumn{2}{c}{ Supply } \\
\cline { 2 - 4 } Origins & $\mathbf{D}_{\mathbf{1}}$ & $\mathbf{D}_{2}$ & $\mathbf{D}_{\mathbf{3}}$ & $\mathbf{1 3}$ \\
$\mathbf{O}_{\mathbf{1}}$ & ${ }^{2} 13$ & 21 & ${ }^{11} 14$ & $\mathbf{2 0}$ \\
$\mathbf{O}_{2}$ & ${ }^{5} 8$ & ${ }^{15} 12$ & $\mathbf{5}$ & $\mathbf{5}$ \\
$\mathbf{O}_{3}$ & ${ }^{5} 15$ & 17 & $\mathbf{1 1}$ \\
Demand & $\mathbf{1 2}$ & $\mathbf{1 5}$ & \\
\hline
\end{tabular}

- Iteration-3: Now largest time is $T_{3}=15$, therefore the cell $(3,2)$ which contains larger time unit than $T_{3}$ is crossed off. Now all the crossed off cells including the crossed off cell in this stage is shown in Table 7.

Table 7. All the crossed off cells.

\begin{tabular}{|c|c|c|c|c|}
\hline \multirow{2}{*}{ Origins } & \multicolumn{3}{|c|}{ Destinations } & \multirow{2}{*}{ Supply } \\
\hline & $\mathbf{D}_{1}$ & $\mathbf{D}_{2}$ & $\mathbf{D}_{3}$ & \\
\hline $\mathbf{O}_{1}$ & ${ }^{2} 13$ & 21 & ${ }^{11} 14$ & 13 \\
\hline $\mathbf{O}_{2}$ & ${ }^{5} 8$ & ${ }^{15} 12$ & & 20 \\
\hline $\mathbf{O}_{3}$ & ${ }^{5} 15$ & & & 5 \\
\hline Demand & 12 & 15 & 11 & \\
\hline
\end{tabular}


Now no loop can be formed originating from the cell $(3,1)$. Thus the obtained solution $x_{11}=2, x_{13}=11, x_{21}=$ $5, x_{22}=15, x_{31}=5$ is optimum and the optimum shipment time is $\max \{13,14,8,12,15\}=15$ time units.

\subsection{Example-2}

Some equipment is to be transported from three origins to three destinations. The supply at the origins, the demand at the destinations and the time of shipment are shown in Table 8.

Table 8. Data of the example-2.

\begin{tabular}{|c|c|c|c|c|}
\hline \multirow{2}{*}{ Origins } & \multicolumn{3}{|c|}{ Destinations } & \multirow{2}{*}{ Supply } \\
\hline & $\mathbf{D}_{1}$ & $\mathbf{D}_{2}$ & $\mathbf{D}_{3}$ & \\
\hline $\mathbf{O}_{1}$ & 15 & 7 & 25 & 12 \\
\hline $\mathbf{O}_{2}$ & 8 & 12 & 14 & 17 \\
\hline $\mathbf{O}_{3}$ & 17 & 19 & 21 & 7 \\
\hline Demand & 12 & 10 & 14 & \\
\hline
\end{tabular}

It is required to find the optimum plan for shipment to minimize the total time of shipment.

\subsubsection{Initial Basic Feasible Solution}

From Table 8, it is seen that total supply and total demand are equal. Hence the given transportation problem is a balanced one. Obtaining IBFS for Example-2 using the Proposed Algorithm is shown in Table 9.

Table 9. Initial basic feasible solution using proposed algorithm.

\begin{tabular}{|c|c|c|c|c|c|c|c|c|}
\hline \multirow{2}{*}{ Origins } & \multicolumn{3}{|c|}{ Destinations } & \multirow{2}{*}{ Supply } & \multirow{2}{*}{ LE } & & \multirow{2}{*}{ RDI } & \multirow[b]{3}{*}{ (?) } \\
\hline & $\mathrm{D}_{1}$ & $\mathrm{D}_{2}$ & $\mathrm{D}_{3}$ & & & & & \\
\hline $\mathbf{O}_{1}$ & ${ }^{2} 15_{8}$ & ${ }^{10} 7_{6}$ & $25_{0}$ & 12 & 25 & (2) & (2) & \\
\hline $\mathbf{O}_{2}$ & ${ }^{3} 8_{3}$ & $12_{5}$ & ${ }^{14} 14_{11}$ & 17 & 14 & (6) & (2) & -- \\
\hline $\mathbf{O}_{3}$ & ${ }^{7} 17_{4}$ & $19_{2}$ & $21_{4}$ & 7 & 21 & (0) & (2) & (2) \\
\hline Demand & 12 & 10 & 14 & & & & & \\
\hline \multirow[t]{2}{*}{ LE } & 17 & 19 & 25 & & & & & \\
\hline & (4) & (1) & (7) & & & & & \\
\hline \multirow[t]{2}{*}{ CDI } & (4) & (1) & -- & & & & & \\
\hline & (4) & (4) & -- & & & & & \\
\hline
\end{tabular}

It is seen that the number of basic variables is $5(=3+3-1)$ and the set of basic cells do not contain a loop. Thus the solution obtained is a basic feasible solution and the initial basic feasible solution is $x_{11}=2, x_{12}=10$, $x_{21}=3, x_{23}=14, x_{31}=7$ and the shipping time of basic cells are $t_{11}=15, t_{12}=7, t_{21}=8, t_{23}=14, t_{31}=17$.

Therefore, in order to complete the shipment, it takes the time $T_{1}=\max \left\{t_{11}, t_{12}, t_{21}, t_{23}, t_{31}\right\}=\max \{15,7,8,14$, $17\}=17$ units of time.

\subsubsection{Optimality Test}

- Iteration-1: Now largest time is $T_{1}=17$, therefore the non basic cells, $(1,3),(3,2)$ and $(3,3)$ containing larger time units than $T_{1}$ are crossed off. These crossed off cells are shown in Table $\mathbf{1 0 .}$

Table 10. All the crossed off cells.

\begin{tabular}{|c|c|c|c|c|}
\hline \multirow{2}{*}{ Origins } & \multicolumn{3}{|c|}{ Destinations } & \multirow{2}{*}{ Supply } \\
\hline & $\mathrm{D}_{1}$ & $\mathrm{D}_{2}$ & $\mathrm{D}_{3}$ & \\
\hline $\mathbf{O}_{1}$ & ${ }^{2} 15$ & ${ }^{10} 7$ & 25 & 12 \\
\hline $\mathbf{O}_{2}$ & ${ }^{3} 8$ & 12 & ${ }^{14} 14$ & 17 \\
\hline $\mathbf{O}_{3}$ & ${ }^{7} 17$ & 19 & 21 & 7 \\
\hline Demand & 12 & 10 & 14 & \\
\hline
\end{tabular}


Now no loop can be formed originating from the cell $(3,1)$. Thus the obtained solution $x_{11}=2, x_{12}=10, x_{21}=$ $3, x_{23}=14, x_{31}=7$ is optimum and the optimum shipment time is $\max \{15,7,8,14,17\}=17$ units of time.

\section{Comparative Study of the Results}

After obtaining an IBFS by the proposed method, the obtained result is compared with the solution obtained by other existing methods that how many number of iterations are to be required to obtain an optimum solution. This is shown in Table 11.

Table 11. Numer of iterations required to obtain optimum time.

\begin{tabular}{ccccccc}
\hline Example & Optimum Time & NWCM & LCM & VAM & EDM & Proposed Method \\
\hline $\mathbf{1}$ & $\mathbf{1 5}$ & $\mathbf{4}$ & 3 & 3 & 3 & 3 \\
$\mathbf{2}$ & $\mathbf{1 7}$ & $\mathbf{3}$ & 3 & $\mathbf{2}$ & $\mathbf{1}$ & $\mathbf{1}$ \\
\hline
\end{tabular}

\section{Conclusion}

In this writing, an algorithm has been discussed to solve time minimizing transportation problems. Efficiency of the developed algorithm is also been justified by solving numerical problems. During this process, a comparative study among the proposed method and the other existing methods is also carried out; where it is observed that the proposed method requires minimum number of iterations to obtain the optimal transportation time. Therefore, the proposed algorithm claims its wide application in the field of optimization in solving the time minimizing transportation problem.

\section{References}

[1] Khan, A.R. (2011) A Resolution of the Transportation Problem: An Algorithmic Approach. Jahangirnagar University Journal of Science, 34, 49-62.

[2] Khan, A.R. (2012) Analysis and Resolution of the Transportation Problem: An Algorithmic Approach, M.Phil. Thesis, Department of Mathematics, Jahangirnagar University, Savar.

[3] Khan, A.R., Vilcu, A., Sultana, N. and Ahmed, S.S. (2015) Determination of Initial Basic Feasible Solution of a Transportation Problem: A TOCM-SUM Approach. Buletinul Institutului Politehnic Din Iasi, Romania, Secţia Automatica si Calculatoare, LXI (LXV), 1, 39-49.

[4] Khan, A.R., Banerjee, A., Sultana, N. and Islam, M.N. (2015) Solution Analysis of a Transportation Problem: A Comparative Study of Different Algorithms. Bulletin of the Polytechnic Institute of Iasi, Romania, Section Textile, Leathership, in Press.

[5] Uddin, M.S., Anam, S., Rashid, A. and Khan, A.R. (2011) Minimization of Transportation Cost by Developing an Efficient Network Model. Jahangirnagar Journal of Mathematics \& Mathematical Sciences, 26, 123-130.

[6] Islam, Md.A., Khan, A.R., Uddin, M.S. and Male, M.A. (2012) Determination of Basic Feasible Solution of Transportation Problem: A New Approach. Jahangirnagar University Journal of Science, 35, 101-108.

[7] Islam, Md.A., Haque, Md.M. and Uddin, Md.S. (2012) Extremum Difference Formula on Total Opportunity Cost: A Transportation Cost Minimization Technique. Prime University Journal of Multidisciplinary Quest, 6, 125-130.

[8] Babu, Md.A., Helal, Md.A., Hasan, M.S. and Das, U.K. (2013) Lowest Allocation Method (LAM): A New Approach to Obtain Feasible Solution of Transportation Model. International Journal of Scientific and Engineering Research, 4, 1344-1348.

[9] Babu, Md.A., Helal, Md.A., Hasan, M.S. and Das, U.K. (2014) Implied Cost Method (ICM): An Alternative Approach to Find The Feasible Solution of Transportation Problem. Global Journal of Science Frontier Research-F: Mathematics and Decision Sciences, 14, 5-13.

[10] Babu, Md.A., Das, U.K., Khan, A.R. and Uddin, Md.S. (2014) A Simple Experimental Analysis on Transportation Problem: A New Approach to Allocate Zero Supply or Demand for All Transportation Algorithm. International Journal of Engineering Research \& Applications (IJERA), 4, 418-422.

[11] Uddin, Md.M., Khan, A.R., Roy, S.K. and Uddin, Md.S. (2015) A New Approach For Solving Unbalanced Transportation Problem Due To Additional Supply. Bulletin of the Polytechnic Institute of Iasi, Romania, Section Textile, Leathership, in Press. 
[12] Ahmed, M.M., Tanvir, A.S.M., Sultana, S., Mahmud, S. and Uddin, Md.S. (2014) An Effective Modification to Solve Transportation Problems: A Cost Minimization Approach. Annals of Pure and Applied Mathematics, 6, 199-206.

[13] Anam, S., Khan, A.R., Haque, Md.M. and Hadi, R.S. (2012) The Impact of Transportation Cost on Potato Price: A Case Study of Potato Distribution in Bangladesh. The International Journal of Management, 1, 1-12.

[14] Das, U.K., Babu, Md.A., Khan, A.R., Helal, Md.A. and Uddin, Md.S. (2014) Logical Development of Vogel’s Approximation Method (LD-VAM): An Approach to Find Basic Feasible Solution of Transportation Problem. International Journal of Scientific \& Technology Research (IJSTR), 3, 42-48.

[15] Das, U.K., Babu, Md.A., Khan, A.R. and Uddin, Md.S. (2014) Advanced Vogel’s Approximation Method (AVAM): A New Approach to Determine Penalty Cost for Better Feasible Solution of Transportation Problem. International Journal of Engineering Research \& Technology (IJERT), 3, 182-187.

[16] Hammer, P.L. (1969) Time Minimizing Transportation Problems. Naval Research Logistics Quarterly, 16, $345-357$. Http://Dx.Doi.Org/10.1002/Nav.3800160307

[17] Sharma, J.K. and Swarup, K. (1977) Time Minimizing Transportation Problem. Proceeding of Indian Academy of Sciences, 86, 513-518.

[18] Uddin, M.S. (2012) Transportation Time Minimization: An Algorithm Approach. Journal of Physical Science, 16, 59-64.

[19] Uddin, Md.M., Rahaman, Md.A., Ahmed, F., Uddin, M.S. and Kabir, Md.R. (2013) Minimization of Transportation Cost on the Basis of Time Allocation: An Algorithmic Approach. Jahangirnagar Journal of Mathematics \& Mathematical Sciences, 28, 47-53.

[20] Ahmed, M.M. (2014) Algorithmic Approach to Solve Transportation Problems: Minimization of Cost and Time. M. Phil. Thesis, Department Of Mathematics, Jahangirnagar University, Savar.

[21] Garfinkel, R.S. and Rao, M.R. (1971) The Bottleneck Transportation Problem. Naval Research Logistics Quarterly, 18, 465-472. Http://Dx.Doi.Org/10.1002/Nav.3800180404

[22] Szwarc, W. (1971) Some Remarks on the Transportation Problem. Naval Research Logistics Quarterly, 18, $473-485$. Http://Dx.Doi.Org/10.1002/Nav.3800180405

[23] Nikolic, I. (2007) Total Time Minimizing Transportation Problem. Yugoslav Journal of Operations Research, 17, 125-133. Http://Dx.Doi.Org/10.2298/YJOR0701125N 